\title{
Hemifacial display of emotion in the resting state
}

\author{
M.K. Mandal, H.S. Asthana, S.K. Madan and R. Pandey \\ Department of Psychology, Banaras Hindu University, India \\ Correspondence to: M.K. Mandal at above address
}

The human face at rest displays distinguishable asymmetries with some lateralization of emotion or expression. The asymmetrical nature of the resting face was examined by preparing hemifacial composites, left-left, right-right, along with normal facial orientation. The left side and right side composites were constructed by using the lateral half of one side of the face and its mirror-reversal. The left side facial composites were found to be more emotional than the right side or normal facial orientations of neutral expressions.

Keywords: Emotional lateralization - Hemifacial composites - Neutral facial state

\section{INTRODUCTION}

One hundred years ago, Darwin (1890) suggested that the two sides of the human face are not equally expressive. Wolff (1933) subsequently noted that the right side of the human face offers social or public expressions whereas the left side of the face reveals hidden, personalized feelings. There is also some experimental literature which suggests that emotions are expressed more intensely on the left side of the face (Sackeim et al., 1978). A split-face composite method, in which a full face is created by the lateral half of one side of the face and its mirror-reversal (Wolff, 1933), has been used to investigate this notion. Neuroanatomically, the left side of the face as compared to the right side is more richly innervated by the fiber projections of the contralateral (i.e. right) hemisphere which is considered to be specialized for emotion processing (Leventhal and Tomarken, 1986). The left side of the face therefore reveals personalized feelings particularly when these are expressed to verbal command.

Although the findings of left-sided facial asymmetry during expression of facial emotion have been attributed to the function of the cerebral hemisphere, it is also possible that non-emotional peripheral factors could be operative in the production of such asymmetries (Borod and Koff, 1990). For example, if the two hemifaces differ in the degree of muscular activity, the hemiface with greater mobility might be perceived as more emotionally expressive. The role of peripheral factors in the production and judgment of neutral expression is however significantly reduced. Yet the resting left hemiface is judged either more happy (Stringer and May, 1981) or miserable (Campbell, 1978) than the right hemiface. These conclusions were however drawn without testing the possible source of affect blend in neutral expression. The present study seeks to examine the asymmetrical nature of neutral facial state with the hypothesis that the left side of the face will be emotionally more involved than either the right side or whole face. Such an examination is intended to identify 'facial leakage' of the general affective state of an individual. It is expected that besides having an enduring effect, every conscious thinking process involves some form of emotional tone (pleasant or unpleasant), and the individual intends to control the emotion with the help of certain display rules (Ekman and Friesen, 1975), for example, neutralizing/deintensifying the appearance of a felt emotion or masking it with the configuration of another emotion. In terms of Wolff's original proposition, the 'public' (right) face may contribute to adhering to display norms. The present study however is not intended to test this proposition.

\section{METHOD}

Expressions of 29 right-handed models (15 male, 14 female) were photographed for their neutrality. The hand preference for each was assessed using a Handedness Inventory (Oldfield, 1971). These photographs were shown to 630 observers for recognition. Only those photographs on which there was consensus of more than $75 \%$ of the observers were selected. In the second step, 100 observers were asked to rate the selected photographs on a 7-point rating scale, with neutral or no emotion being 1 and the intended emotion (happy, sad, fear, anger, surprise, disgust) being 7. If the judgment for a particular photograph was beyond the rating value of 1 the photograph was deleted. Such a procedure for selection of photographs was adapted from Ekman and Friesen (1975). 

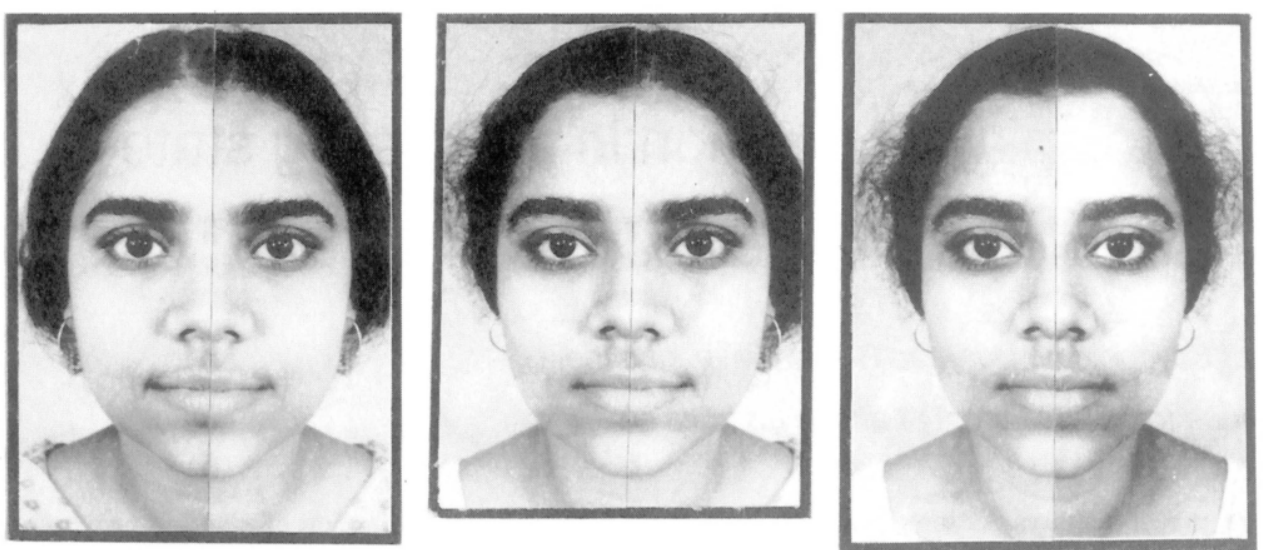

FIG. 1. Left-side composite, normal orientation, and right-side composite respectively, of a resting face.

This process yielded 12 photographs ( 5 male, 7 female, mean age $=24.0$ and S.D. 2.27 years) of neutral facial expressions with no affect bias. These facial photographs were then prepared for original (right-left), right-side, and left-side composite photographs (Fig. 1). The photographs were black and white glossy prints measuring $19 \times 17 \mathrm{~cm}$, and each was a full face photograph of an adult Indian subject. Each selected photograph was printed twice, once in the original orientation (RL) and once in mirror-reversed (LR) orientation. The original and mirror-reversed prints of each photograph were cut vertically through the midline of the face. The midline was determined by using the midpoint of the line between the internal canthi of the eyes and the central vertex of the upper lip. Such a procedure for preparing composite photographs was adapted from Rhodes and Lynskey (1989). It is suggested that "Judgments of facial asymmetry in expression are influenced by biases of perceiver rather than by asymmetry in actual expressions" (Sackeim et al., 1978). In the present study, complete photographs were used to overcome observer bias.

One hundred and forty-eight right-handed male observers (mean age $=22.1$ years, S.D. 3.3 years and mean education $=17.0$ years), 74 observers each for male and female expressors, were asked to rate a photograph on a 5-point bipolar rating scale: pleasant $(+5)$; neutral $(0)$; unpleasant $(-5)$. Life-size photographs depicting neutral expressions were presented before the subjects one by one in a random order.

\section{RESULTS}

The emotion valence data (Table I) were treated with a 2 (expressors: male, female) $\times 2$ (composites: left-left, right-right) factorial ANCOVA design with the normal (right-left) facial orientation being the covariate one. Find- ings with covariate data unadjusted revealed significant main effect of facial composite $(\mathrm{F}=28.8$, df 1,292 , $p<0.001)$. The left-side facial composites were emotionally more valenced than the right-side composites. The main effect of sex and the interaction of sex $\times$ facial composite were nonsignificant. Findings with the covariate data adjusted increased the magnitude of difference between left-side and right-side composites, with emotional valence attributed to the left-side facial composite $(\mathrm{F}=41.7$, df $1,291, p<0.001)$. The departure from neutrality for the photographs towards pleasantness and unpleasantness yielded nonsignificant differences $(p>0.05)$. The frequency of perfect neutral score (zero) chosen for normal facial orientation was significantly higher than left-left facial composite $(Z=<0.01)$. The difference between normal orientation and right-right facial orientation was nonsignificant $(p>0.05)$ in this respect.

\section{DISCUSSION}

Findings suggest that the left side of the face which reveals personalized feelings, pleasant or unpleasant, even in the resting state is not under complete conscious control of the expressor. Besides the original proposition of Wolff,

TABLE I. Mean rating for the emotional valence. ${ }^{1}$ The values of pleasantness and unpleasantness are taken together to obtain the mean rating

\begin{tabular}{lccc}
\hline $\begin{array}{l}\text { Facial } \\
\text { orientation }\end{array}$ & Right-left & Right-right & Left-left \\
\hline $\begin{array}{l}\text { Expressor } \\
\text { Male }\end{array}$ & 1.26 & 1.34 & 1.76 \\
Female & 1.70 & 1.46 & 1.95 \\
\hline
\end{tabular}

1 The greater the value, the greater the valence. 
many other studies have documented more pronounced left-facedness during emotional expression (Campbell, 1986). The greater left hemifacial activity implicates right hemisphere involvement in emotional expression because the fiber projections of the hemifaces are predominantly innervated by the contralateral hemisphere (Sackeim et al., 1978). Clinical studies with brain-damaged patients have provided support for their notion in that right hemisphere-damaged patients are significantly more impaired than left hemisphere-damaged or normal controls when asked to imitate emotional expressions (Borod et al., 1986).

Three studies have reported the asymmetrical nature of the resting face; in the first, the lateral facial composites indicated an asymmetry of the neutral face (Bennett et al., 1987), in the second, neutral expressions were found to be left-sided (Borod and Koff, 1990), and in the third, emotional adjectives were attributed more to left than to right side composites of the neutral face (McGee and Skinner, 1987). The present study indicated that the left side of the face is emotionally more valenced than the right side. The anatomical relationship of the left hemiface with the affect (right) hemisphere may account for such a finding. The right side of the face, in contrast, is under the motor control of the cognitive (left) hemisphere (Rinn, 1984) which exerts an inhibitory effect upon the expression of facial emotion (Gainotti, 1983). The left hemisphere-damaged patients were therefore found to have greater facial activity in terms of emotional expression as compared to the right hemisphere-damaged patients or even normal control subjects (Buck and Duffy, 1980). The conscious control of the right hemiface, designated as public (Wolff, 1933) is rendered perhaps in terms of display norms (Ekman and Friesen, 1975) by neutralizing or deintensifying the emotion effect of the left hemiface.

The question that remains unresolved is how the emotional tone in the left hemiface eludes notice in day-to-day interactions. Gilbert and Bakan (1973) and other investigators (Bruyer and Craps, 1985) have suggested that the hemiface in the perceiver's left visual hemispace largely determines facial judgment. In other words the right side of the expressor's face dominates in face to face interaction, and is the side people pay more attention to (Campbell, 1986). It is possible that such a hemivisual space bias in facial perception is learned in the course of human development which allows a temporal priority of cognition in the understanding of affective expressions (Lazaraus, 1984).

\section{REFERENCES}

Bennett HL, Delmonico RL and Bond CF (1987) Expressive and perceptual asymmetries of the resting face. Neuropsychologia, 25, 681-687.

Borod JC and Koff E (1990) Lateralization for facial emotional behavior: a methodological perspective. International Journal of Psychology, 25, 157-177.

Borod JC, Koff E, Lorch MP and Nicholas N (1986) The expression and perception of facial emotion in brain-damaged patients. Neuropsychologia, 24, 169-180.

Bruyer R and Craps V (1985) Facial asymmetry: perceptual awareness and lateral differences. Canadian Journal of Psychology, 39, 54-69.

Buck R and Duffy RJ (1980) Nonverbal communication of affect in brain-damaged patients. Cortex, 16, 351-361.

Campbell R (1978) Asymmetries in interpreting and expressing a posed facial expression. Cortex, 14, 327-342.

Campbell R (1986) Asymmetry of facial action: some facts and fiction of normal movement. In: The Neuropsychology of Facial Perception and Facial Expression (Ed. R Bruyer), pp. 247-267. Lawrence Erlbaum, Hillsdale, NJ.

Darwin C (1890) The Expression of the Emotions in Man and Animals. D Appletion, New York.

Ekman P and Friesen WV (1975) Unmasking the Face. PrenticeHall, Englewood Cliffs, NJ.

Gainotti G (1983) Laterality of affect: the emotional behaviour of right and left brain-damaged patients. In: Hemisyndromes: Psychobiology, Neurology, Psychiatry (Ed. MS Myslobodsky), pp.175-189. Academic Press, New York.

Gilbert C and Bakan P (1973) Visual asymmetry in perception of faces. Neuropsychologia, 11, 355-362.

Lazaraus RS (1984) On the primacy of cognition. American Psychologists, 39, 124-129.

Leventhal H and Tomarken AJ (1986) Emotion: today's problems. Annual Review of Psychology, 37, 565-610.

McGee A and Skinner M (1987) Facial asymmetry and the attribution of personality traits. British Journal of Social Psychology, 26, 181-184.

Oldfield RC (1971) The assessment and analysis of handedness: the Edinburgh Inventory. Neuropsychologia, 9, 97-114.

Rhodes $G$ and Lynskey M (1989) Emotion in resting face: taking sides. A reply to McGee and Skinner (1987). British Journal of Social Psychology, 28, 273-278.

Rinn WB (1984) The neuropsychology of facial expression: a review of the neurological and psychological mechanisms for producing facial expression. Psychological Bulletin, 95, 52-77.

Sackeim HA, Gur RC and Saucy MC (1978) Emotions are expressed more strongly on the left side of the face. Science, 202, 434-435.

Stringer P and May P (1981) Attributional asymmetries in the perception of moving, static, chimeric, and hemisected faces. Journal of Nonverbal Behavior, 5, 238-252.

Wolff W (1933) The experimental study of forms of expression. Character and Personality, 2, 168-173. 


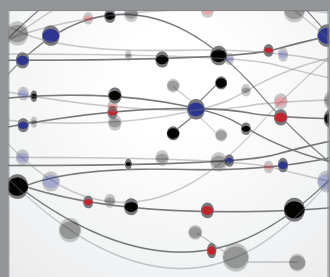

The Scientific World Journal
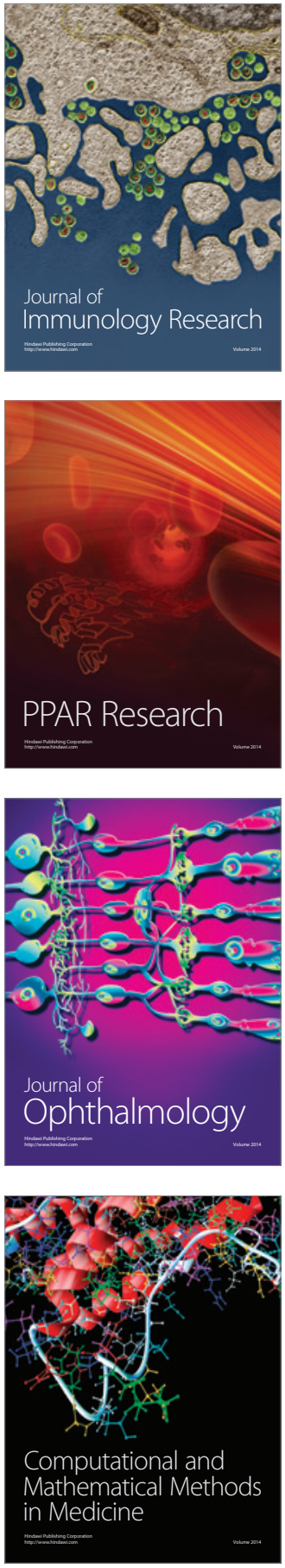

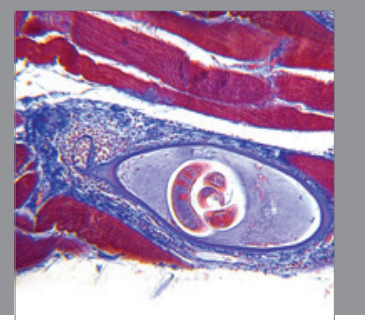

Gastroenterology

Research and Practice
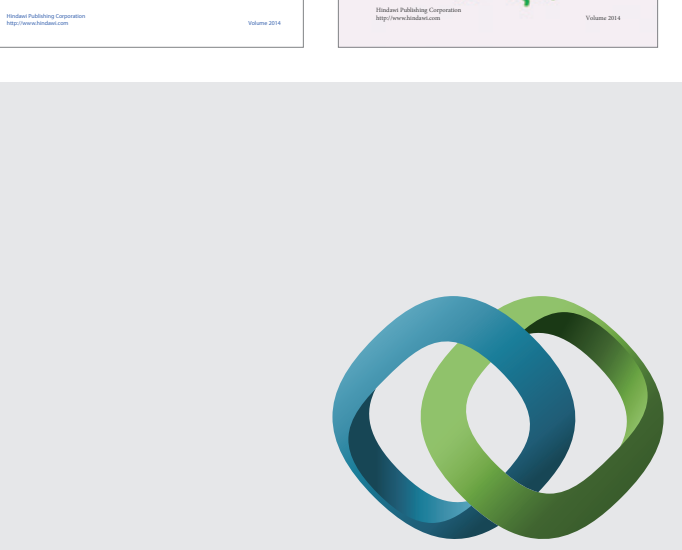

\section{Hindawi}

Submit your manuscripts at

http://www.hindawi.com
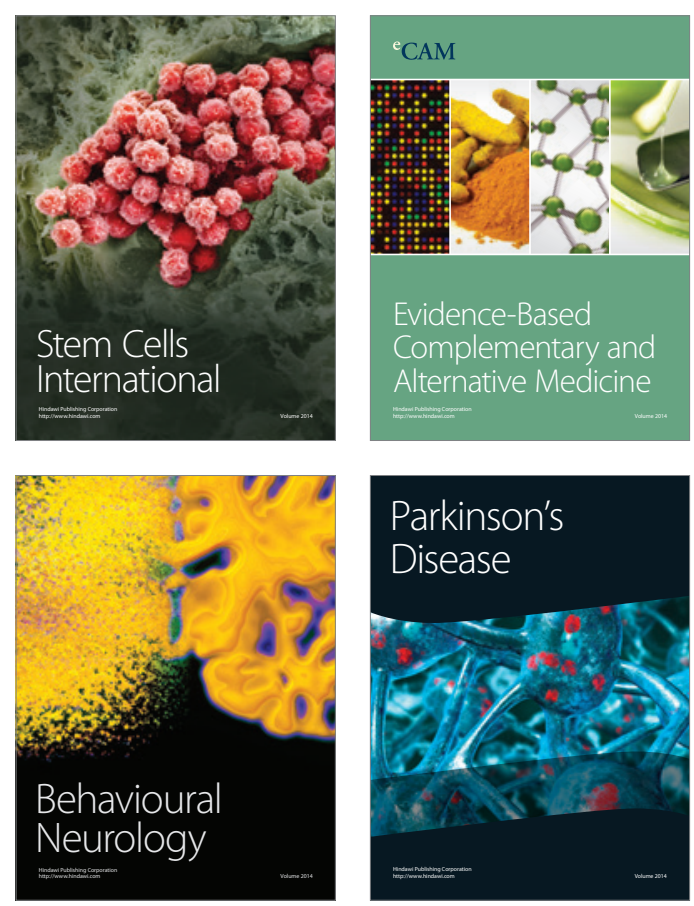

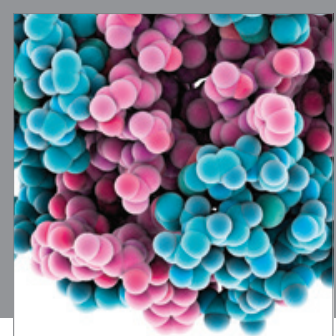

Journal of
Diabetes Research

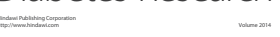

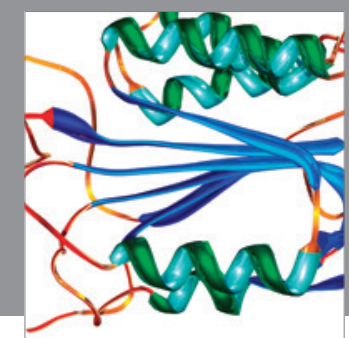

Disease Markers
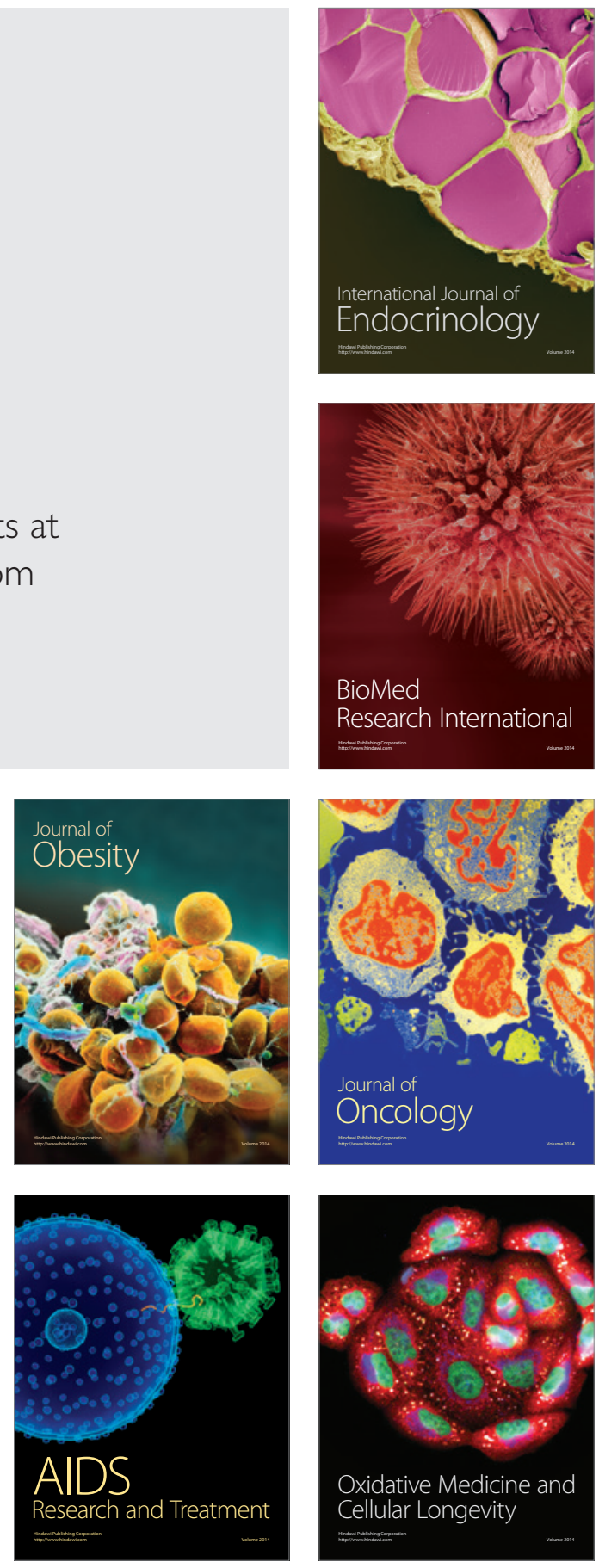